\title{
Therapeutic effects on cartilage metabolism in arthritis as measured by release of proteoglycan structures into the synovial fluid
}

\author{
TORE SAXNE, ${ }^{1}$ DICK HEINEGÅRD, ${ }^{2}$ AND FRANK A WOLLHEIM \\ From the ${ }^{l}$ Department of Rheumatology, University Hospital, Lund; and the ${ }^{2}$ Department of Physiological \\ Chemistry, University of Lund, Lund, Sweden
}

SUMMARY Proteoglycans are molecules that are degraded and released from the articular cartilage into the synovial fluid early in an arthritic process. Such released proteoglycans were quantified by an enzyme linked immunosorbent assay (ELISA). The proteoglycan content in synovial fluid from patients with various knee joint arthritides was constant in two samples withdrawn five days apart. To determine if therapeutic measures were paralleled by effects directly on the articular cartilage the patients were treated with local injections of glucocorticoids. In all patients the glucocorticoids induced a reduction of the proteoglycan content in the synovial fluid, reflecting their effects on the cartilage. In two patients with spontaneous remission of their arthritis a reduction in the proteoglycan content in the synovial fluid was also noted. The quantification of proteoglycans in synovial fluid appears to have potential as a useful tool for monitoring the effects of therapy on cartilage metabolism.

Key words: glucocorticoids, intra-articular injections, enzyme linked immunosorbent assay.

Proteoglycans are, after collagen, the major macromolecules of articular cartilage. They consist of a central protein core to which a large number of highly negatively charged glycosaminoglycan side chains, chondroitin sulphate and keratan sulphate, are covalently attached. The majority of the proteoglycans bind via the globular $\mathrm{N}$-terminal region of their core protein to hyaluronic acid. Thus cartilage contains large aggregates of proteoglycans with molecular weights exceeding $100 \times 10^{6}$, which are entrapped in the collagen network. ${ }^{1}$ A reduction of the proteoglycan content of the cartilage can be demonstrated early in inflammatory or degenerative joint disease. Histologically this can be observed as loss of metachromasia. ${ }^{2}$ It appears that the protein core is proteolytically cleaved and the fragments are free to diffuse out into the synovial fluid. ${ }^{3}$ The detection of proteoglycans in synovial fluid should accordingly be a marker for active cartilage destruction.

Accepted for publication 31 October 1985.

Correspondence to Dr Tore Saxne, Department of Rheumatology, University Hospital, S-221 85 Lund, Sweden.
An ELISA detecting immunoreactive human articular cartilage proteoglycans in synovial fluid has been developed, in line with a previously described assay for dog articular cartilage proteoglycans released into synovial fluid. ${ }^{4}$ This method has potential as a useful tool for monitoring changes in proteoglycan content in synovial fluid longitudinally, e.g., in relation to different therapeutic approaches. The purpose of the present work was to use this assay to study the changes in proteoglycan content in inflammatory knee joint effusions after intra-articular glucocorticoid injections.

\section{Materials and methods}

COLLECTION OF SYNOVIAL FLUID

Eighteen patients (19 knee joints) were studied. One group (A) of nine patients ( 10 knee joints) all had an inflammatory knee joint effusion and had not received glucocorticoid treatment orally or intraarticularly for a minimum period of three months before the trial. None of these patients had been treated with slow acting antirheumatic drugs, and treatment with non-steroidal anti-inflammatory 
drugs (NSAIDs) was not changed during the study. The clinical characteristics of the patients in this group are shown in Table 1 . In most of the patients in this group two initial measurements with a five day interval were made before the glucocorticoid was injected. Joint fluid was then sampled every five days as long as synovial fluid could be withdrawn. Group B represents samples from nine knee joints collected for other purposes and analysed retrospectively for this study. Two joint aspirations were made in these patients and in all cases a relapse of synovitis was present at the second aspiration despite the glucocorticoid therapy. All patients in group B had classical or definite rheumatoid arthritis according to the American Rheumatism Association criteria. ${ }^{5}$ Seven were Waaler-Rose positive (titre $\geqslant 1 / 64)$. Four were treated with chloroquine, one with Proresid (a podophyllin derivative). All were treated with NSAIDs. No glucocorticoids had been given orally or intraarticularly during the three months before the first joint aspiration. The knee joint radiographs in both groups were graded by an independent radiologist according to Larsen-Dale ${ }^{6}$ by comparing the radiographs with standard pictures graded from 0 to 5 , where 5 denotes the most severe joint destruction. The patients in both groups had moderate destruction (Table 1, group A). Joint aspirations were made with a conventional aseptic technique by one investigator for group A and by several investigators for group B. No local anaesthesia was used. The synovial fluid was withdrawn as completely as possible by a $1.2 \mathrm{~mm}$ bore needle. The effusions were collected in sterile EDTA tubes (ethylenediaminetetra-acetate, $5 \mathrm{mmol} / \mathrm{l}$ ), centrifuged within one hour $(1800 \mathrm{~g}, 20 \mathrm{~min}$, twice) to remove cells, and then stored in aliquots at $-80^{\circ} \mathrm{C}$. Patients in group A were given triamcinolone hexacetonide (Lederspan, $10-20 \mathrm{mg}$ ) and those in group $B$ were given betamethasone (Celestona bifas, 6-12 mg).

PREPARATION OF SYNOVIAL FLUIDS

Before analysis all synovial fluids were digested with bovine testis hyaluronidase (Sigma, St Louis, USA) to depolymerise the hyaluronic acid and to remove the glycosaminoglycan side chains of the proteoglycan. A predigestion to reduce the viscosity of the synovial fluid was made by adding $2 \mu \mathrm{l}$ of hyaluronidase $(1 \mathrm{mg} / \mathrm{ml}$ in $0.2 \mathrm{M}$ trometamol (TRIS), $0 \cdot 1 \mathrm{M}$ sodium acetate, $\mathrm{pH} 7 \cdot 0$ ) to $200 \mu \mathrm{l}$ of synovial fluid. After four hours at $37^{\circ} \mathrm{C}$ aliquots $(50 \mu \mathrm{l}) \mathrm{r}$ 'ere removed and mixed with $400 \mu \mathrm{l}$ of $0 \cdot 1 \mathrm{M}$ trometamol $\mathrm{HCl}(\mathrm{pH} \mathrm{8.0)}$ containing $50 \mu \mathrm{l}$ of hyaluronidase. After four hours at $37^{\circ} \mathrm{C}$ samples were frozen and kept at $-20^{\circ} \mathrm{C}$ until analysis.
PREPARATION OF ANTIGEN

Proteoglycans were extracted from human articular $\overrightarrow{\vec{G}}$ cartilage obtained at autopsy within a few hours after death and purified by caesium chloride density $\frac{\bar{\sigma}}{\sigma}$ gradient centrifugation under the dissociative conditions of $4 \mathrm{M}$ guanidinium chloride.' Proteo- $\stackrel{\overparen{\Phi}}{\bar{\Phi}}$ glycan preparations to be used for immunisation were also purified by chromatography on Sephadex G-200 eluted with 4 M guanidinium chloride.?

PREPARATION OF ANTISERUM Antibodies were raised in a goat immunised with native human articular cartilage proteoglycan monomer. Initially, $1.5 \mathrm{mg}$ of proteoglycancr monomer in Freund's complete adjuvant was injected subcutaneously. Two injections a month apart with $1.0 \mathrm{mg}$ of proteoglycan monomer in $\overrightarrow{0}$ Freund's incomplete adjuvant then sufficed to raise $\vec{\supset}$ antibodies in a titre sufficient for use in the immuno- $\vec{c}$ assay. The serum was used without further purification. It did not react with any human plasmaprotein, showing that it was specific.

ENZYME LINKED IMMUNOSORBENT ASSAY ( E L IS A )

An ELISA with specificity for human articular cartilage proteoglycan monomer has been de- ڤ్ veloped in accordance with a previously developed $\frac{\Phi}{\Phi}$ method for dog articular cartilage proteoglycan. ${ }^{4} \overrightarrow{\vec{F}}$ Falcon polyvinyl microtitre plates (Falcon 3912) were used. The wells were coated ( 24 hours, room $\vec{\partial}$ temperature) with $200 \mu \mathrm{l}$ of human articular cartilage proteoglycan monomer $(0.5 \mu \mathrm{g} / \mathrm{ml})$. Before coating the proteoglycans were treated with chon- $\overline{2}$ droitinase ABC (Seikagaku Kogyo Co Ltd, Tokyo, 을 Japan) to remove glycosaminoglycan side chains for their use as antigen in the assay. Samples were dissolved $(1 \mathrm{mg} / \mathrm{ml})$ in $0.1 \mathrm{M}$ trometamol and $0.1 \mathrm{M}$ sodium acetate ( $\mathrm{pH} 7.3)$ containing $0.01 \mathrm{unit} / \mathrm{ml}$ of 윽 chrondroitinase $\mathrm{ABC}$, and digested for four hours at $37^{\circ} \mathrm{C}$. The solutions of chondroitinase treated proteoglycans $(1 \mathrm{mg} / \mathrm{ml})$ were diluted in $0.05 \mathrm{M} \mathrm{N}$ sodium carbonate ( $\mathrm{pH} 9.5)$ before coating the plates overnight. The plates were extensively rinsed with $\mathrm{N}$ $0.15 \mathrm{M}$ sodium chloride and $0.05 \%(\mathrm{w} / \mathrm{v})$ Tween $20 \omega$ to remove unbound proteoglycan. Samples of synovial fluid $(115 \mu \mathrm{l}$, pretreated with hyaluronidase $)$ were mixed with $115 \mu$ l of a $1 / 1000$ dilution of goat $\stackrel{\oplus}{\Phi}$ antihuman articular cartilage proteoglycan monomer in $0.1 \mathrm{M}$ sodium chloride, $0.05 \mathrm{M}$ sodium phosphate, and 0.05\% Tween 20 (pH 7.5). After $\frac{P}{\Phi}$ preincubation for 24 hours at room temperature $\stackrel{\odot}{\Phi}$

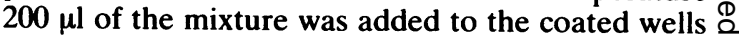
of the microtitre plate. After incubation for $60 \%$ minutes at room temperature the plates were rinsed $尺$ as above and $200 \mu \mathrm{l}$ of a dilution of rabbit antigoat 
Therapeutic effects on cartilage metabolism in arthritis 493

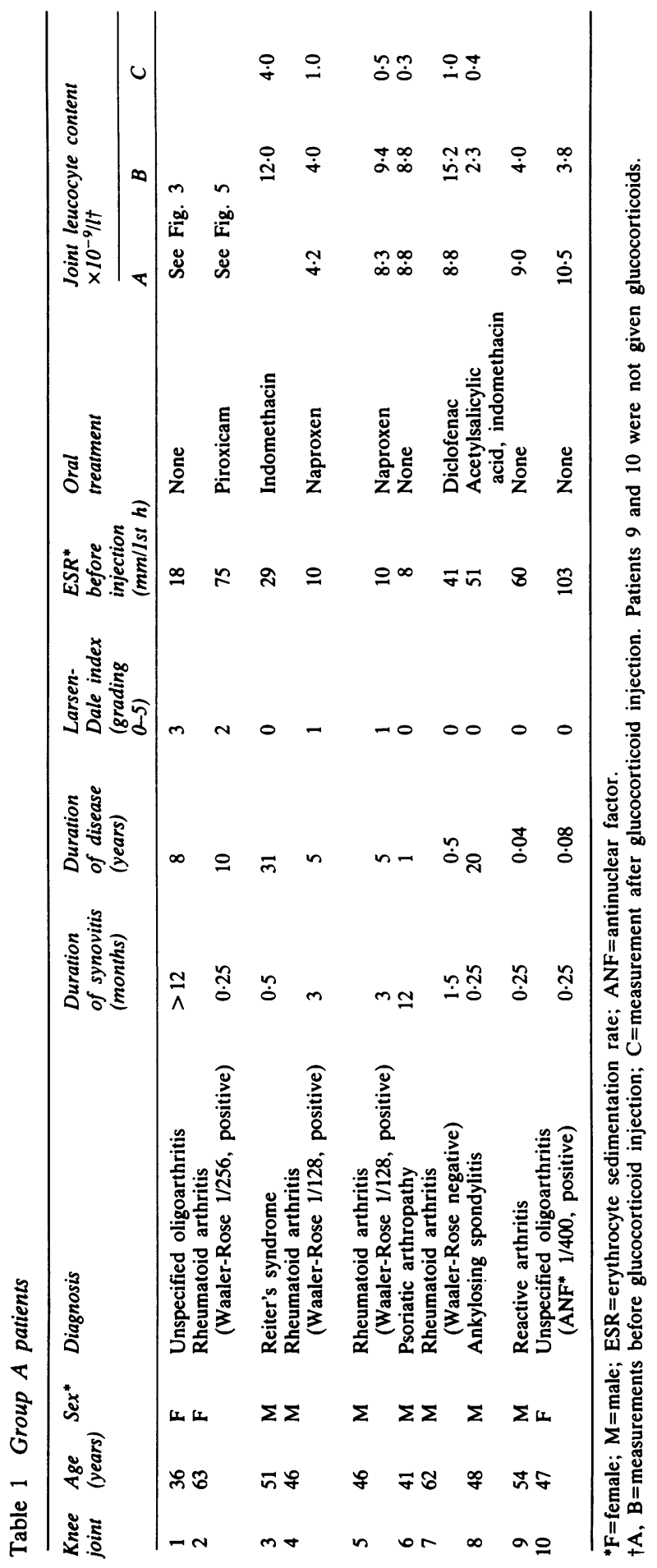


IgG conjugated with alkaline phosphatase (Orion Diagnostica, Helsinki, Finland) in $0.1 \mathrm{M}$ sodium chloride, $0.05 \mathrm{M}$ sodium phosphate, $0.05 \%$ Tween 20 , and $2 \mathrm{mg} / \mathrm{ml}$ of bovine serum albumin ( $\mathrm{pH} \mathrm{7.5)}$ was added. After 60 minutes at room temperature the plates were again rinsed and $200 \mu$ l of enzyme substrate, $1 \mathrm{mg} / \mathrm{ml}$ of $p$-nitrophenyl phosphate in 1 $M$ diethanolamine, $\mathrm{pH} 9.8$, containing $0.5 \mathrm{mM}$ $\mathrm{MgCl}_{2}$, was added. The absorbance at $405 \mathrm{~nm}$ was measured in a Multiscan filter photometer (Flow laboratories, USA) immediately and after 60 minutes of incubation at room temperature. The increase in absorbance was used for calculations. A standard curve using hyaluronidase digested (as described for synovial fluids) human articular cartilage proteoglycans was included in each microtitre plate. All samples were analysed in triplicate, and the mean value was used for calculations.

\section{Results}

In knee joints with clinically stable synovitis both the proteoglycan concentration and the total amount remained constant when aspirations were made twice with a five day interval before the $\vec{F}$ glucocorticoid injection (Fig. 1). Apparently, removal of synovial fluid in itself did not affect the amount of proteoglycan fragments in the synovial fluid. After the glucocorticoid injection the proteoglycan content in the synovial fluid was much lower $\varrho$ (Fig. 1). This finding was seen in all effusions except के one (Fig. 1) which initially had a very low content of $\vec{\circ}$ proteoglycans. Group B showed the same pattern, with stable proteoglycan concentrations in the two patients who received no injection and much lower concentrations in effusions after glucocorticoid injections (Fig. 2). Fig. 3 shows a marked decrease in of proteoglycan content in knee joint No 1 after the glucocorticoid injection. The second injection 15 if days later resulted in a slight further decrease. Four months after the first injection the proteoglycan $\frac{\circ}{\partial}$ content in the synovial fluid was still low despite a relapse of the synovitis, but five months later when a second relapse occurred the proteoglycan content in $ळ$ the synovial fluid had again risen to the intial $\overrightarrow{0}$ amount. Two patients (knee joints Nos 9 and 10,
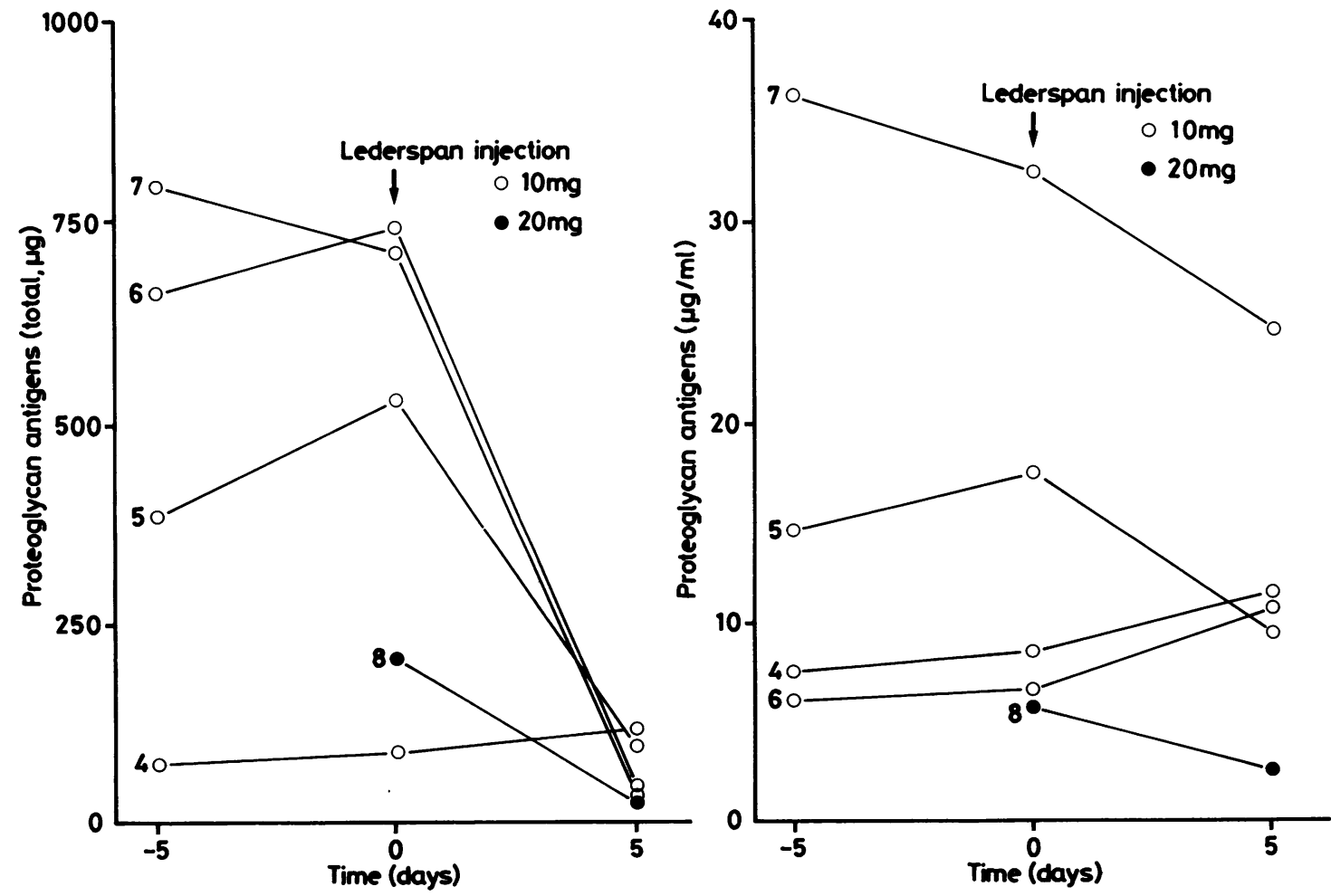

Fig. 1 Proteoglycan content (left) and concentration (right) in knee joint synovial fluid samples from five patients. The arrow denotes the time at which glucocorticoids were injected. The numerals refer to the knee joints listed in Table 1. 


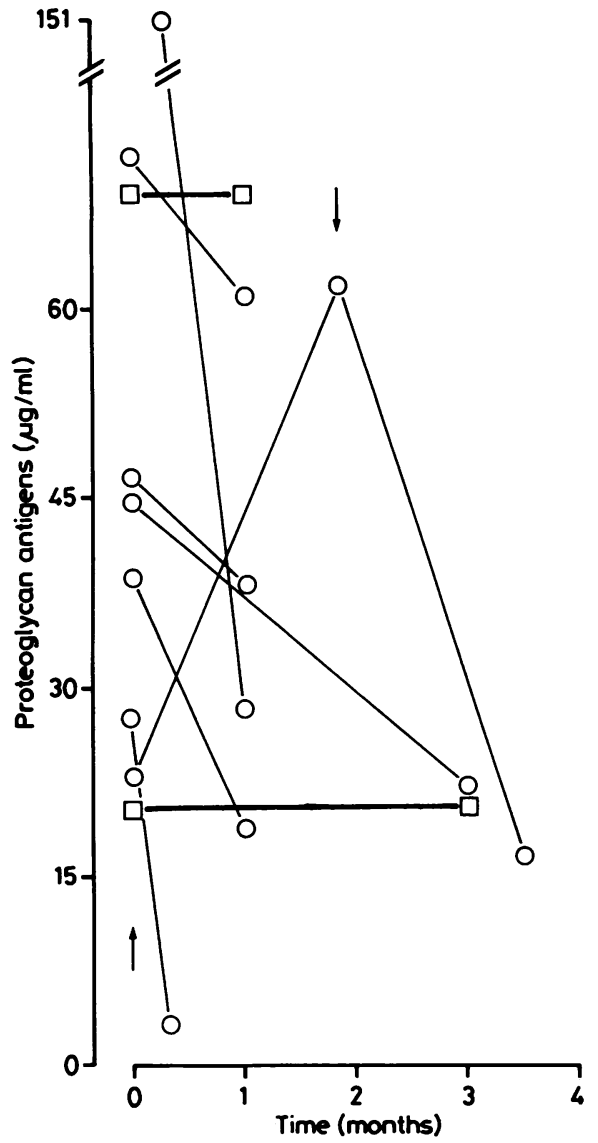

Fig. 2 Proteoglycan concentrations in knee joint synovial fluid samples from seven patients before and after corticosteroid injection $(\mathrm{O})$ and from two patients who received no glucocorticoid injection ( $\square)$.

Fig. 4) had acute arthritides, which spontaneously improved between the first and second joint aspiration. After the glucocorticoid injection no synovial fluid could be aspirated. In knee joint No 3 (Fig. 4) a dramatic clinical improvement of the knee joint accompanied the fall in proteoglycan content in the effusion, while other affected joints remained unchanged, as judged clinically.

The changes in joint leucocyte contents closely paralleled those in proteoglycan contents (Fig. 3), with the exception of knee joint No 2 (Fig. 5). Although the proteoglycan content decreased, the joint leucocyte content remained almost constant after the glucocorticoid injection. In this patient with a Waaler-Rose positive rheumatoid arthritis the glucocorticoids were not effective in suppressing the synovitis, and a surgical synovectomy was later performed.
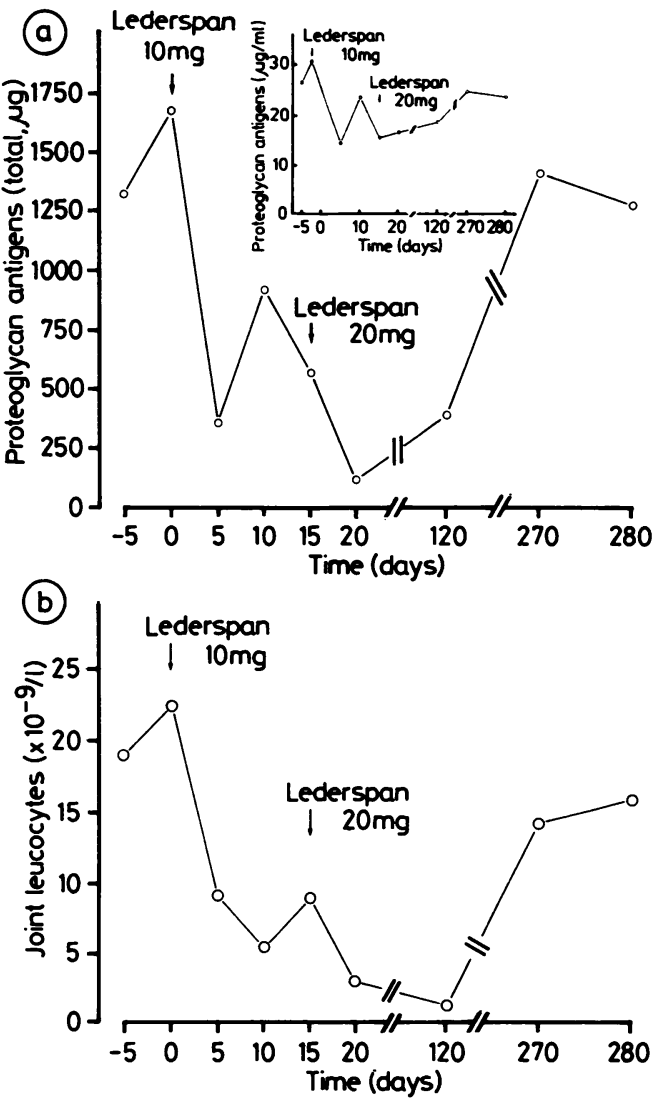

Fig. 3 Proteoglycan content (a) and concentration ((a) inset) in synovial fluid samples from one knee joint (No 1) of a patient given glucocorticoid injections. The arrows denote the times of injections. Figure (b) shows the changes in joint leucocyte content.

\section{Discussion}

Intra-articular injections of glucocorticoids effectively suppress joint inflammation. ${ }^{8}$ Their effects on the articular cartilage are less well established. Recently, however, several investigators have studied this problem by different approaches. Cocultures of cartilage and synovial tissue have shown that glucocorticoids can reduce cartilage degradation. ${ }^{9}$ The glucocorticoids seem to act on the synovial membrane by reducing the production of mediators causing cartilage degradation, i.e., catabolin and perhaps proteolytic enzymes. ${ }^{10}$ In a carrageenan induced synovitis, in studies of artificial synovial cavities in mice, hydrocortisone sodium succinate (a soluble preparation) reduced and hydrocortisone acetate (an insoluble preparation) enhanced proteoglycan loss from 


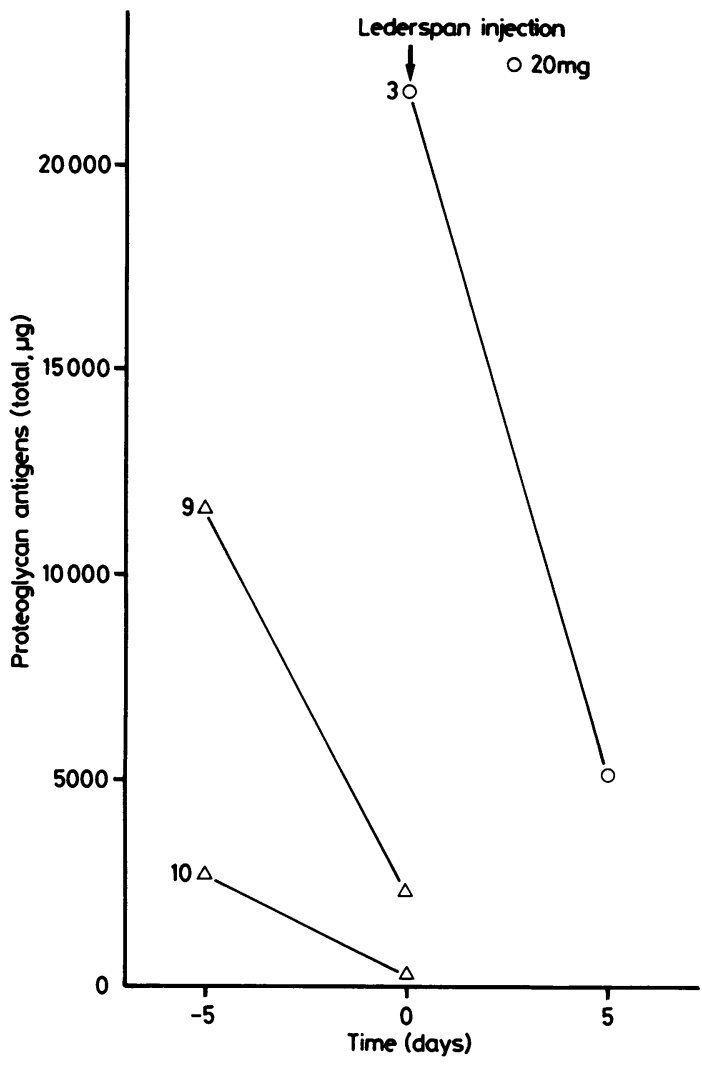

Fig. 4 Proteoglycan content in knee joint synovial fluid samples from two patients with spontaneously improving acute arthritides $(\triangle)$ and in the synovial fluid from one patient with Reiter's syndrome $(O)$, who clinically improved in the injected joint but not in other joints. The numerals refer to the knee joints listed in Table 1.

implanted autologous cartilage as determined by a colorimetric procedure. ${ }^{11}$ When injected into the inflamed lining tissue both preparations reduced the proteoglycan loss. Another study with histological methods has shown reduction of cartilage degradation after triamcinolone hexacetonide injection into the knee joints of rabbits with an antigen induced arthritis. ${ }^{12}$ In healthy knee joints of rabbits, on the other hand, injection of hydrocortisone acetate has been shown to suppress the $\left[{ }^{3} \mathrm{H}\right]$ glycine incorporation in the cartilage, which according to the authors suggests a reduced synthesis of matrix components by the chondrocyte, in line with the known protein catabolic action of glucocorticoids in other tissues. ${ }^{13}$ In man only a few inconclusive radiographic studies have been performed. Chandler and Wright showed progressive reduction of the cartilage depth in knee joints after

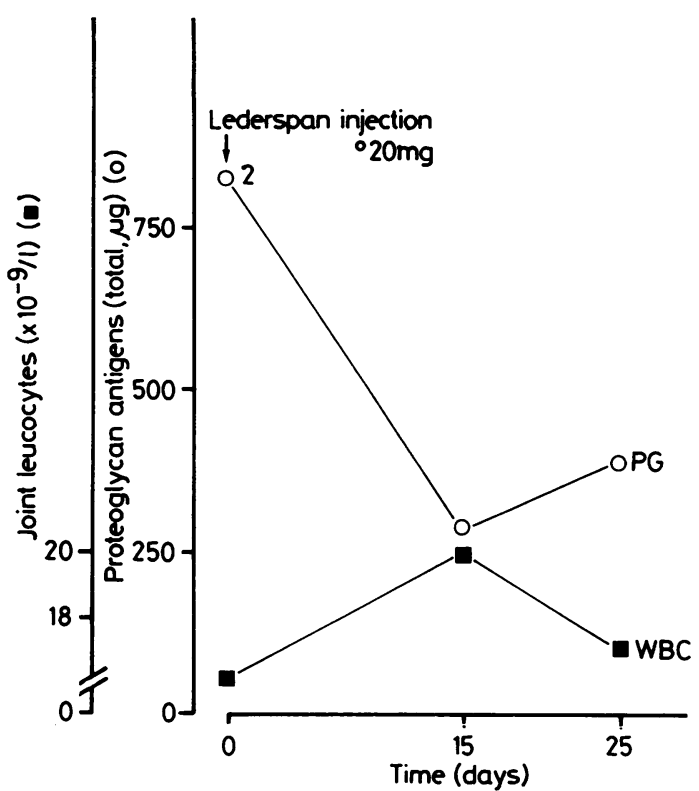

Fig. 5 Proteoglycan (PG) content $(\mathrm{O})$ and joint leucocyte content $(\square)$ in knee joint synovial fluid samples from one patient (joint No 2) who did not benefit clinically from the glucocorticoid injection. The proteoglycan content decreased, while the joint leucocyte content remained constant.

intra-articular injection of hydrocortisone despite clinical improvement. ${ }^{14}$

In the present study we use release of proteoglycans from the cartilage matrix as a marker for active processes. Previously, dogs with induced osteoarthritis of one knee joint were shown to have a higher concentration of proteoglycans in the diseased joint compared with that in the control joint. ${ }^{4}$ The most striking finding in the present study is the decrease in proteoglycan content in the synovial fluids after the glucocorticoid injections, suggesting a reduced liberation of proteoglycans from the cartilage. In a $\mathcal{N}$ previous study of joint destruction the cartilaginous $N$ origin of the proteoglycans in the synovial fluid was indicated. When the cartilage mass became lower, as visualised by $x$ ray, the proteoglycan content of the synovial fluid was markedly reduced. ${ }^{15}$

The quantification of proteoglycans in the synovial fluid presents some problems. Provided that the proteoglycans are liberated at a constant rate, the concentration of fragments will depend on the volume of the synovial fluid. This volume is difficult to measure. Isotope techniques have been tried ${ }^{16}$ but these are not suited for repeated measurements as in the present trial. In group $A$ a standardised N

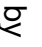

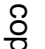

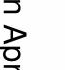

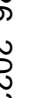
$\underset{0}{0}$

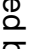


procedure was used to minimise sampling errors, most important when dealing with small effusions. The results from patient 6 (Fig. 1) show the importance of considering the synovial fluid volume in these studies. In this patient the changes in concentration and estimated total amount of proteoglycans differed considerably. In general, however, the trend is similar whether concentration or total amount is studied. Another potential problem when using immunoassay to quantify macromolecules could be that the fragments liberated react differently with the antibodies. In the present study, however, several of the samples analysed at different dilutions gave identical values, showing that the standards and the samples had reacted similarly with the antibodies.

The results presented show that glucocorticoids injected intra-articularly reduce the content of proteoglycan antigenic structures in the synovial fluid in inflammatory knee joint disease. When spontaneous remission of a synovitis occurs the content of proteoglycans is also reduced. Whether the effects of the glucocorticoid injections are caused by interference with the synthesis of proteoglycans or by inhibition of their degradation is not answered by the present study. It should be noted, however, that during tissue culture most newly synthesised matrix molecules are retained in the cartilage, favouring the latter mechanism. ${ }^{17}$ It is possible that the glucocorticoids inhibit production of catabolin in the inflamed synovium. ${ }^{10}$ The stimulus to the chondrocytes to catabolise proteoglycans would then decrease. The present investigation does not allow any conclusions about the long term effects of glucocorticoid injections, nor about the long term prognosis of the disease in a particular joint. It is possible that studies of the release of other cartilage matrix molecules may provide better prognostic tools.

Grants were obtained from Folksams Yrkesskadors Stiftelse, the Swedish Medical Research Council $(05668)$, the Faculty of Medicine, University of Lund. Greta och Johan Kocks stiftelser. Alfred Österlunds Stiftelse, Riksförbundet mot Reumatism. Föreningen för Bistånd åt Vanföra i Skåne, and Lasarettets i Lund Fonder. We are grateful to Dr Holger Pettersson for examining the radiographs and to Siv Valtersson for skilful technical assistance.

\section{References}

1 Heinegård $\mathrm{D}$, Paulsson $\mathrm{M}$. Structure and metabolism of proteoglycans. In: Piez K. Reddi H, eds. Extracellular matrix biochemistry. Neu York: Elsevier/North Holland, 1984: 277328.

2 Edwards C G. Chrisman O D. Articular cartilage. In: Albright J A. Brand R A, eds. The scientific basis of orthopaedics. New York: Appleton-Century-Crofts, 1979: 313-47.

3 Inerot S. Studies on cartilage proteoglycans in aging and degenerative joint disease. Lund University. 1983. (Thesis).

4 Heinegård D. Inerot S, Wieslander J, Lindblad G. A method for the quantification of cartilage proteoglycan structures liberated to the synovial fluid during developing degenerative joint disease. Scand J Clin Lab Invest. 1985; 45: 421-7.

5 Ropes M W. Bennet G A. Cobbs S. Jacox R. Jessar R A. Diagnostic criteria for rheumatoid arthritis: 1958 revision. Ann Rheum Dis 1959; 18: 49-53.

6 Larsen A. Dale K. Standardized radiological evaluation of rheumatoid arthritis in therapeutic trials. In: Dumonde D C, Jasani M K. eds. The recognition of antirheumatic drugs. Lancaster: MTP Press, 1978: 285-92.

7 Wieslander J. Heinegård D. Immunochemical analysis of cartilage proteoglycans. Antigenic determinants of substructures. Biochem J 1979; 179: 35-45.

8 Hollander J L. Arthrocentesis and intrasynovial therapy. In: McCarthy D J. ed. Arthritis and allied conditions. Philadelphia: Lea and Febiger. 1979: 402-14.

9 Steinberg J J. Kincaid S B. Sledge C B. Inhibition of cartilage breakdown by hydrocortisone in a tissue culture model of rheumatoid arthritis. Ann Rheum Dis 1983; 42: 323-30.

10 Sheppeard H. Pilsworth L M C, Hazleman B, Dingle J T. Effects of antirheumatoid drugs on the production and action of porcine catabolin. Ann Rheum Dis 1982; 41: 463-8.

11 Sedgwick A D. Sin Y M. Moore A R. Edwards J C W, Willoughby D A. Effects of local administration of hydrocortisone on cartilage degradation in vivo. Ann Rheum Dis 1984; 43 : 418-20.

12 Wollheim F A. Henricsson A S. Telhag H T. Triamcinolone hexacetonide prevents joint destruction in antigen induced arthritis [Abstract]. XVI International Congress of Rheumatology. Sydney. Australia. 1985.

13 Mankin H J. Conger K A. The acute effects of intra-articular hydrocortisone on articular cartilage in rabbits. $J$ Bone Joint Surg 1966: 48A: 1383-8.

14 Chandler G N. Wright V. Deleterious effect of intra-articular hydrocortisone. Lancet 1958; ii: 661-3.

15 Saxne T. Heinegård D. Wollheim F A. Pettersson H. Difference in cartilage proteoglycan level in synovial fluid in early rheumatoid arthritis and reactive arthritis. Lancet 1985; ii: 127-8.

16 Rekonen A. Oka M. Kuikka J. Measurement of synovial fluid volume by a radioisotope method. Scand J Rheumatol 1973; 2: 33-5.

17 Paulsson M. Sommarin Y, Heinegård D. Metabolism of cartilage proteins in cultured tissue sections. Biochem $J$ 1983: 212: $659-67$. 